\title{
Beyond the Cultural Borders of the Dining Room: A Reader-Oriented Approach to A. R. Gurney's The Dining Room
}

\author{
Esraa Jalal Jawad Al-Gawhari*
}

Department of English, College of Arts, University of Baghdad, Iraq

Corresponding Author: Esraa Jalal Jawad Al-Gawhari, E-mail: israajalal@yahoo.com

\section{ARTICLE INFO}

Article history

Received: December 02, 2017

Accepted: January 06, 2018

Published: February 28, 2018

Volume: 9 Issue: 1

Advance access: January 2018

Conflicts of interest: None

Funding: None

Key words:

Reader-Response Criticism,

Gurney,

The Dining Room,

WASP,

Culture

\begin{abstract}
A. R. Gurney's The Dining Room is a work basically written to address issues related to the White Anglo-Saxon Protestant (henceforth WASP) culture. The work is rich with elements (the structure, the setting, the characters, and the themes), inviting to the WASP audience to interact with it, recognizing their cultural identity. The present study aims at proving that those elements can also endow the text with wider horizons when perceived by other audiences through supporting the symbol of the dining room. The study examines them in an attempt to see their effects on the WASP audience. Then, it views them as factors adding to the text a universal touch.
\end{abstract}

\section{INTRODUCTION}

The contemporary audience of any author plays an important role in deciding the way how s/he shapes his/her text. This role is further magnified when the author writes a text subjectively communicating issues of resonance among his community. The text becomes the author and his audience's territory of mutual memories and dreams. The author structures the elements of the text to serve his intentions to send specific cultural messages. However, audience outside the author's milieu can grasp universal messages especially if the elements of the text supportively present a symbol of universal appeal. The focus of the present study is A. R. Gurney's The Dining Room. Gurney addresses his White Anglo-Saxon Protestant (henceforth WASP) audience successfully that his play has an effect on them whenever acted. However, through the symbol of the dining room, the text is endowed with universal dimensions. The aim of the study is to highlight the significance of the room through a thorough examination of the elements of the text. Among the other elements, the room stands importantly once as a WASP heritage and then as a universal dominion.

\section{READER-RESPONSE CRITICISM}

Reader-response critics have approached the process of reading through various perspectives in an attempt to establish an understanding of the relationship between the reader and the text. It is only through this relation that the text acts as a living entity with effective mechanisms of interaction with the readers' minds. Stanley Fish argues that "any school of criticism that would see a work of literature as an object, claiming to describe what it is and never what it does, is guilty of misconstruing the very essence of literature and reading. Literature exists when it is read" (Murfin 333).

Wolfgang Iser distinguishes between "the 'implied reader', whom the text creates for itself through 'response inviting structures'... and 'the actual reader' who brings to the act of reading a certain stock of experiences which colour the reading process" (Selden 121-122). Through the directive faculty of its implied reader, the text communicates with the responsive reader. This communication is a dynamic process of self-correction. The responsive reader develops signifieds which s/he must then constantly modify. Throughout the act of reading, $\mathrm{s} / \mathrm{he}$ gets involved in filling gaps in the text with his/her own interpretations of characters and their 
situations based on ambiguous signs transmitted by the text. The images and the senses the reader builds in an early stage of reading are reassessed in a later stage (Selden 124).

Other critics postulate that the readers' response is guided not by the text itself but rather by their own psychological needs (Murfin 337). Norman Holland states that readers find in the text their own "identity theme" (Murfin), hence approaching the text individually to find out through the text their own "characteristic patterns of desire" (Murfin). Stanley Fish similarly places extra weight on the readers' role in shaping the dimensions of the text, but proposing that readers approach the text collectively to find their "cultural identity" (Murfin 338). He argues that some interpretive communities like college students reading a text as a class assignment share interpretive strategies that exist prior the act of reading (Murfin).

The author's 'identity theme' can also be communicated through the work, whether being read as a text or performed onstage. If successfully captured by contemporary audiences, it could raise awareness of a specific 'cultural identity' that would be difficult to be overlooked by future audiences, reviewers, and students. However, audiences can still communicate dynamically with the text, discovering horizons beyond any individual and cultural specifications. That can be best exemplified by tackling A. R. Gurney's The Dining Room.

\section{A. R. GURNEY'S THE DINING ROOM}

In The Dining Room, Gurney transmitted his 'identity theme' to his contemporary WASP audience, leading them to find their own 'cultural identity'. WASP was coined by the American sociologist, E. Digby Baltzell (1915 -1996). An introduction to Baltzell and his views of the WASP culture is essential to any scholarly reading of the text. Both Gurney and Baltzell came from elite WASP backgrounds; they attended St. Paul's prep school in New York, graduated from an Ivy League college, and pursued primarily academic careers; they harbored regret for their culture's loss of influence; Baltzell believed that the WASP's dominance could have formed a strong pillar for society, had not they turned their backs on authority and become a privileged caste; Baltzell said that his opinion was inspired by Alexis de Tocqueville whose classic analysis of Old Regime and French Revolution revealed that the violent revolution was resulted from the degeneration of nobility into a caste when refusing to assimilate new men of power (Mcconachie 102-103). He advocates safeguarding equality of opportunities within a society that preserves its class hierarchy; he considers hierarchy a necessity for social order and gradual change, hence scolding his class for abandoning its values and social commitment (Mcconachie, 103). On the same ground, Gurney lamented the decline of his class, saying that he is obsessed with

the contrast between the world and the values I was immersed in when I was young and the nature of the contem-porary world. The kind of protected, genteel, in many ways warm, civilized, and fundamentally innocent world in which I was nurtured didn't seem in any way to prepare me for the late twentieth century. I tend to write about people who are operating under these old assumptions, but are confronting an entirely different system of values. (Bennetts 5)
Gurney conveys his lamentation through the text of the The Dining Room. A thorough examination of the text can divulge his communication with his WASP contemporary audience.

As the title suggests, the play is set in a dining room. The well-furnished room with "a good, warm oriental rug"(297) is in the middle of a masked surrounding that suggests " $a$ sense of..void" (297) and "a limbo outside" (297); no details are shown from the rooms beyond the two entrances upstage, the swinging door leading to the pantry and the kitchen and the archway leading to the rest of the house. The room stands aloof there, as though "it were on display in some museum, many years from now" (297). It has French doors catching the early morning light and displaying a lovely garden and flowering crabs. The focal point of the room, the dining ta-ble, is associated with luxurious dinner parties and "long, leisurely breakfast. as opposed to instant coffee on Eastern Airlines" (299). So, it stands in contrast to the quick pace of modern life and symbolizes a heritage of the past when values and familial ties were strong.

The room serves as a unifying factor linking eighteen vignettes concerned with the lives of different families belonging to the WASP culture. In the stage directions, Gurney recommends casting "the play with people of different ages, sizes, and shapes, as long as they are all good actors" (297). That could invoke more WASP audience to identify with those characters that belong to three generations: grandparents, parents, and their children. In vignette IX, one can see the calm grandfather who accepts to finance his grandson's education at a prestigious school in New York:

GRANDFATHER. Why would you want to meet anyone from New York?

NICK. Well they're more sophisticated, Gramp. They'll buff me up.

GRANDFATHER. I don't think you need buffing up. You'll have to give us better reasons.

NICK. Um. they have advanced Latin there. And indoor hockey rink. And beautiful grounds and surroundings.

GRANDFATHER. Don't we? Don't we have beautiful surroundings? Why do we have to go away to have beautiful surroundings?. [I] didn't finish. Yes well I didn't do too badly. Without a high Episcopal boarding school, and indoor hockey rink.

NICK. But you're a self-made man, Gramp.

GRANDFATHER. Oh is that what I am? And what are you? Don't you want to be self-made? Or do you want other people to make you? Hmmm? Hmmm? What've you got to say to that?

NICK. (Squashed.) I don't know. I don't want to go! Really! I never wanted to go! I want to stay home with all of you!.

GRANDFATHER. Go on. Enjoy yourselves, all of you. Leave town, travel, see the world. (322-324)

On the other hand, in vignette $\mathrm{V}$, the audience is introduced to Grace, the nagging mother, who wants to bend her daughter, Carolyn, to her will and make her join the Junior 
Assemblies. The latter refuses and insists to accompany her maid aunt to the theatre to see Saint Joan. They have a tensioned mother-daughter relationship, revealing a generation gap.

There is a big difference between the approach adopted by the gentle grandfather with his grandson and that by the domineering mother with her daughter. This associates wisdom and quietude with the elderly generations.

The vignettes also show different attitudes among people belonging to the same generation. The dining room is used as a touchstone of those differences. In vignette I, a husband does not prefer a house with a dining room, telling a real estate agent that they will never use the room, adding that in previous houses, his wife has used the dining table to sort the laundry. He requests to be shown a more contemporary house. In contrast, in vignette IV, the husband rebukes his wife for using the dining table as a desk to type her term paper. He treasures the table as a family heritage and wants to preserve it for giving dinner parties in significant occasions. He rejects his wife's suggestion to use the kitchen to accommodate such gatherings, insisting that this is not appropriate even if everyone does it. In vignette II, Arthur and Sally, a brother and sister try to reach agreement upon dividing up family items including a dining table. They delay the decision concerning the table as both like to have it. They feel gravitated right to it, showing their attachment to the past it represents. The brother does not have a place for the table in his tiny apartment and his children probably will not want it. Still, if he has it, he will find a place for it. Hence, some people from the second generation are still attached to their tradition, facing the indifference of their kids to their attachment. The lack of place here also stands for the lack of space of time for family rituals associated with dining rooms, denoting the encroachment of the quick rhythm of modern life over their mode of living. This is also shown in vignette VII where the architect convinces his client, a psychiatrist, to dispense with the dining room and use a limited eating area instead to save a space for his clinic:

Settle behind your desk module here. You read, you listen to music. Soon-buzz - a patient arrives. You turn off the music, put aside your book, and buzz him in through the sound-proof doors. He flops on the couch here ... tells you his dream, you look out the window here, he leaves, you write him up, buzz in the next. Soon it's time for lunch. You go in here, have lunch with the wife, or one of the kids and maybe stroll back in here for a nap. More buzzes, more patients, and soon it's time for a good easy cooperative supper with your family. (315)

The room is also associated with childhood memories that are either negative or positive. The architect says that it has been a torture to have one's meals in the room: "those endless meals, waiting to begin, waiting for the dessert, waiting to be excused. it was brutal. I remember one time I came to the table without washing my hands, and my father- $-(\mathrm{He}$ stops.)" (315-316). But, the psychiatrist finds it a place with "resonance" (315).

For kids, the room is a new frontier that can be trodden only by adhering to disciplines. Then, it becomes a gateway for the world of adults. In vignette III, the kids are eager to have their meals in the room and the father teaches them table manners to be ready to have their dinner with their parents there. In vignette VI, Michael, a twelve years old kid, tells Aggie, the servant, that he listens to adult stories at the dining table: "I know a lot. I eat dinner here in the dining room now. I listen I know that my Uncle Paul is drinking himself into oblivion. And Mrs. Williams has a tipped uterus" (312).

Gurney also uses the two-act structure of his play to be suggestive of the WASP culture decline. In Act I, mostly, he shows examples of people preserving and appreciating the stature of their culture through their manners and attachment to their past like the brother and sister of vignette II and the grandfather of vignette IX. The Act ends with vignette XI where a family tries to help their old mother, who suffers from Alzheimer, remember them and they uselessly use the dining table as a reminder of the happy time they have spent together. The old mother's lost memory symbolically stands for the fading aspects of the WASP's culture. It indicates the first generation's loss of control over their family domain and the second generation's failure to maintain their heritage. It paves the way for Act II that begins with vignette XII where Sarah, who belongs to the third generation, shows her abhorrence of the dining room and its etiquette. She takes a chance summoning her friend, Helen, and two boys to have liquor together while her parents are absent from home. When asked by Helen to spend their time at the dining room, she repulsively replies: "No way. Absolutely no way. In here? I'd get all up tight in here. Having boys in the dining room? Jesus, Helen. You really are a wimp sometimes" (334). Moreover, She abhors having meals there, saying: "it sucks, if you want to know. It sucks out loud" (333).

In about the middle of Act II, The acronym WASP is mentioned explicitly for the first time in the play in vignette XIV. The vignette presents a situation that expresses the gist of the play. Tony is working on a classroom project for Anthropology. He asks Aunt Harriet to show him some items related to their habits like the finger bowls that they used to dip their fingers into them at meals between the salad and the dessert. She enthusiastically gives him detailed information about their lifestyle. But, when she knows the purpose beyond his project, she becomes angry:

Aunt Harriet. Anthropology. Heavens! (She starts to return items to her tray.) What does that have to do with this?

Tony. Well you see we're studying the eating habits of various vanishing cultures. And my professor suggested I do a slide show on us.

Aunt Harriet. Us?

Tony. The Wasps. Of Northeastern United States.

Aunt Harriet. I see

Tony. You can learn a lot about culture from how it eats. Aunt Harriet. (With increasing coldness.) Such as what? Tony. Well. Consider the finger b owls, f or example. There you have an almost neurotic obsession with cleanliness, reflecting the guilt which comes w ith the last stages of capitalism. 
Aunt Harriet. I think I'll ask you to leave, Tony. Out! Right now! Before I telephone long distance to your mother!. Vanishing culture, my eye! I forbid you to mention my name in the classroom! Or show one glimpse of my personal property! (338)

The scene involves satiric presentation of the WASP people, revealing their responsibility for the decline of their culture. The reference to capitalism reminds one of vignette III where the father gets annoyed with what his son's teacher, Miss Kelly, has told the kids about issues related to the government and the economic situation; she says that the government should do something to help poor people suffering from depression. He objects, saying that if they are given money, they will not want to work. He adds that Miss Kelly may be an excellent teacher, but they don't need her to teach them politics. He even dismisses her advice about the significance of punctuality, arguing that it is not important to reach school on time as much it is to have a pleasant breakfast. This reveals the shallowness of some of the WASP people. They don't have core values to help them build an everlasting basis for their dominance. The precarious foundation of the WASP supremacy is symbolized at vignette $\mathrm{X}$ when Margery tries to fix her old dining table, she discovers that the table is not an original antique, but a copy based on the English.

In vignette XVII, an old man, Harvey, feeling he will die soon, gives instructions to his eldest son, Dick, on how to arrange for his funeral. This definitely reinforces the touch of decline in the play. Harvey tells Dick that they can talk in the dining room because nobody will disturb them there: "nobody comes near a dining room anymore. Nowadays people eat in kitchens, or in living rooms, standing around, balancing their plates like jugglers. Soon they'll be eating in bathrooms" (346-347). The abandonment of the dining room suggests the negligence of cultural rituals associated with it. Though, for many, those rituals are torturing, they are originally meant to secure familial solidarity that is fading in the modern time. This makes it difficult for WASP people to be socially effective.

Abandonment and slackening of family ties are shown in vignette $\mathrm{XV}$ through a conversation between a daughter, Meg, and her old father, Jim. She has abandoned her home and wanted to settle in her parents' home for a few months because she feels lost due to the troubled relation with her husband. They both have affairs with other persons. Their children suffer from instability; they keep coming and going from one residence to another. Jim does not welcome her staying at the family home, urging her to make effort to save her marriage the way her mother did when he had gone through an affair. But, she tells him "that's your generation, Dad" and he replies "that's every generation. every generation has to make an effort" (340). But, she reveals that she is lesbian and recently has had an affair with another woman. Jim, the traditional father, who keeps having meals at the dining room, does not consent with the life his daughter leads.

In both acts there are vignettes tackling the theme of betrayal. In vignette VIII, Peggy and Ted betray their spouses and plan to elope together, if their betrayal is exposed. In vi- gnette XIII, Kate receives her lover, Gordon, at home while her husband is away in Europe. This stresses the weakness of family structure.

The play ends with Ruth, in vignette XVIII, expressing her dream of having an abundant party at the dining room:

Lately I've been having this recurrent dream. We're giving this perfect party. We have our dining room back, and Grandmother's silver, before it was stolen, and Charley's mother's royal blue dinner plates, before the movers dropped them, and even the finger bowls, if I knew where they were. And I've invited all favorite people. Oh I don't mean just our old friends. I mean everyone we've ever known and liked. (351)

Ruth's dream is that of many WASP people. That is why the play always has resonance among them. In "Faded Virtues", Brooke Allen describes the reaction of an older WASP friend who saw the play in the past; saying that she reacted passionately to it and said that it "just brought back too many painful memories" (Allen). After watching the play in 2007, Brooke stated that What makes watching The Dining Room so much more poignant in 2007 than it was in 1981 is the fact that then, WASP culture was dying, while today it is really and truly dead. This truth kept being brought home to me throughout the play and was made the more piquant because by coincidence I ran into a cousin of mine at the theater, with whom, throughout the 1960s and 1970s, I had partaken of many a Thanksgiving dinner in the dining room of the family manse, complete with all the WASP trappings right down to the fingerbowls. We agreed that it made us sad to think that that part of our lives was so definitively over, though I certainly would not want to live that way now; it's just that we miss the stability it represented, and it was nice to have it all to come back to when we wanted to, so long as there was an escape route. Now it's all gone forever, and an unprecedentedly big and rich new type of social elite has moved in to fill the social vacuum. We are living in another Gilded Age, far grosser and more bloated than the last one, and Gurney's old-style WASPS with their faded virtues and faintly ridiculous pretensions have gone up in smoke--sadly or not, depending on your view. (Allen) Other perceivers of the play focus on the satirical vein running in the play. Alvin Klein, in "THEATER REVIEW; Around the Table Life Keeps Changing", describes the WASP milieu of the play as one peopled by patronizing, snobbish people who are "the mothers and fathers of repression and concealment", hinging on the superficial sphere of life (Klein).

Although the play addresses the WASP audience in the first place, the text is capable of furnishing platforms for other perspectives and transmitting signals to different audiences. As people share the same human truth, any piece of art can deliver universal messages.

The structure of the play pays the attention of any perceiver to its scenic transition:

The blending and overlapping of scenes have been carefully worked out to give a sense of both contrast and flow. When there is no blending of scenes, one should follow another as quickly as possible. The play should never degenerate into a series of blackouts. (298) 
This gives a sense of continuity and a quick shift of episodes. It is the wheel of life everlastingly moving in the same spot. It shapes life with both fixity and instability. This is further enhanced by Gurney's recommendation of choosing six actors of different ages and appearances to act various roles. This makes one "observe the characters in terms of that reincarnation theory, that we run into all the same people lifetime after lifetime, but in completely different relationships" (Gates). Another factor that widens the scope of the play is the stage direction that "actual food. should not be served" (298). Gurney's purpose is to make the audience focus on the people and the situations, not on food. But, this could be motivating to different audiences to imagine meals of their preference furnishing the dining table.

The scenic technique also attracts producers and actors to revive the play. As it requires six people to play about 50 characters, players find it an opportunity to "show off their quick-change skills, as they go from portraying, say, a giddy kid at a birthday party in one scene to a doddering grandfather in the next" (Morrow). That is why Soulpepper Theater Company presented the play on 14 Feb 2015. Hence, professional readers of the text can find points of interests in the play not related to the WASP culture.

The play tackles themes of wide appeal like infidelity, generation-gap, the decline of values, and the past versus the present. These issues are tackled in a background where the dining room stands as an eminent symbol that is perceived differently by the characters who keep "trying to break it up or repurpose it" (Morrow): one finds it similar to a church, "a place filled with solemn rites and sacred objects-precious silverware and bone china- where people come to commune, to celebrate or to confess" (Morrow), another appreciates it as an antique piece of furniture, some consider it a boring, torturing place, and others feel that there is nothing better in this world than dining there with the family and enjoying delicious meals.

\section{CONCLUSION}

The most significant element in A. R. Gurney's The Dining Room is its place, the dining room. Gurney intends it to be a WASP territory, holding their past memories and dreams. Its association with them would make audiences approach it only in relation to the issue of white supremacy and the changing factors shaping politics and economy. However, within the structure of the play, the room stands as a dynamic symbol whose implications extend the WASP domain.

The room stands for the past and its traditions and values. Like the characters, audiences from different parts of the world where the quick pace of modern life has drastically affected familial habits ${ }^{1}$, can be roughly divided into ones yearning for the past and others advocating the current style of living. In view of that, their attitudes towards the room will be decided.

The scenic transition technique adopted in the play is a supportive element that enriches the symbolism of the room through exhibiting it within the contexts of 18 vignettes. The vignettes present themes of wide appeal related to the individual and the family. Moreover, each vignette gives a story involving an attitude or more towards the room. The room becomes a multifaceted object, intriguing audiences to formulate their own attitudes towards it based on their personal experiences and psychological needs.

\section{END NOTE}

1. As an Iraqi reader, I feel touched by the play as Gurney's dining room has reminded me of the dining room in my grandfather's house that has been long abandoned, holding memories of family occasions related to me by my mother.

\section{REFERENCES}

Allen, Brooke. "Faded Virtues.” New Criterion 26.3 (2007): 51+. Literature Resource Center. Web. 24 Nov. 2015.

Bennetts, Leslie. "His Obsession is a Culture in Decline." New York Times, 30 May 1982: 4-5.

Gates, Anita. "Meals of imagined bounty." New York Times, 12 May 2013: 10 (L). World History in Context. Web. 26 July 2017.

Gurney, A. R. "The Dining Room.” Plays from The Contemporary American Theater, edited by Brooks McNamara, A Signet Classic, 2002, pp.293-351.

Klein, Alvin. "THEATER REVIEW; Around the Table, Life Keeps Changing. "New York Times, 21 Sept. 1997. World History in Context. Web. 26 July 2017.

McConachie, Bruce. "The Dining Room: A Tocquevillian Take on the Decline of WASP Culture." A. R. Gurney: A Casebook. Ed. Arvid F. Sponberg. New York: Routledge, 2004. 101-109. Print.

Morrow, Martin. "Ode to the vanishing WASP lifestyle." Globe \& Mail [Toronto, Canada], 17 Feb. 2015: L2. World History in Context. Web. 26 July 2017.

Murfin, Ross C., ed. Case Studies in Contemporary Criticism: Nathaniel Hawthorne: The Scarlet Letter. New York: Bedford/St. Martin's: 2006. Print.

Selden, Raman. Practicing Theory and Reading Literature. New York: Harvester Wheatsheaf, 1989. Print. 